\title{
Modulation of Trophoblast Cell Death by Oxygen and EGF
}

\author{
Jonathan Perkins, ${ }^{1}$ Justin St. John, ${ }^{2}$ and Asif Ahmed ${ }^{1}$ \\ ${ }^{1}$ Department of Reproductive and Vascular Biology \\ ${ }^{2}$ Reproductive Biology \& Genetics Group, The Medical School, University of Birmingham, Birmingham, UK \\ Accepted October 14, 2002
}

\begin{abstract}
Background: Preeclampsia, a maternal hypertensive disease, is characterized by shallow invasion of the maternal spiral arterioles resulting in hypoxia/reperfusion type insult; however, the molecular mechanism is unknown. The aim of this study was to determine the mechanism of altered oxygen tension or inhibition of phosphatidylinositol-3-kinase (PI3K) on trophoblast survival and to investigate the effect of epidermal growth factor (EGF) on maintaining cellular integrity.

Materials and Method: We have used flow cytometry, immunoblotting, and fluoroimmunocytochemistry to study apoptosis in a characterized, spontaneously transformed first trimester extravillous-like trophoblast cell line that exhibits many characteristics of in vivo trophoblast.

Results: Time-dependent exposure of first trimester extravillous-like trophoblast to all oxygen tensions tested promoted dissipation of the mitochondrial membrane potential
\end{abstract}

$\left(\psi_{\mathrm{m}}\right)$ and resulted in a significant increase in cell death by 48 $\mathrm{hr}$ as determined by dual staining flow cytometry. Western blot analysis revealed expression of cleaved caspase- 3 and caspase-9 increased with time with hypoxia and hyperoxia promoting the greatest elevation indicating that longer duration of exposure to a change in oxygen tension causes increased apoptosis via a mitochondrial-mediated pathway. Disruption of the anti-apoptotic PI3K pathway by LY294002 $(40 \mu \mathrm{M})$, its specific inhibitor, caused further significant dissipation of the $\psi_{\mathrm{m}}(p<0.01)$ and cleavage of caspase-3. EGF was able to maintain the $\psi_{\mathrm{m}}$ and to prevent cleavage of caspase- 3 even in the presence of LY294002, indicating that its survival effects were independent of the PI3K pathway. Conclusions: These results suggest that inhibition of the PI3K/Akt pathway can sensitize first-trimester trophoblastlike cells into oxygen-induced cell death and that EGF exerts its anti-apoptotic effect independently of PI3K/Akt.

\section{Introduction}

Placental development is a tightly regulated, dynamic process that involves coordinated vascular remodeling of the decidua (interstitial invasion) and maternal spiral arterioles (endovascular invasion) by extravillous trophoblast (1-3). Preeclampsia, a maternal hypertensive disease that affects $7 \%$ of first-time pregnancies (4), is characterized by shallow invasion of the spiral arterioles. It is known that interstitial invasion in preeclampsia is not altered, but that the endovascular invasion is compromised and that invading trophoblast fail to develop a more endotheliallike phenotype (5) or reduce their expression of transforming growth factor $\beta 3$ (6). Despite this, it is still unclear why endovascular invasion fails to occur sufficiently in this disease and if a molecular trigger exists for entry into a program of pathologic development.

The level of oxygen experienced by the fetus and fetal tissues during pregnancy is known to affect many aspects of placental formation (7) and regulates the expression of key angiogenic growth factors such as vascular endothelial growth factor and

Address correspondence and reprint requests to: Asif Ahmed, Department of Reproductive \& Vascular Biology, The Medical School, University of Birmingham, Edgbaston, Birmingham, B 15 2TT, United Kingdom. Phone: $+(44) 121414$ 2660; fax: $+(44)$ 121414 2732; e-mail: a.s.ahmed@bham.ac.uk placenta growth factor (8). During the first 5-10 weeks of gestation, cytotrophoblasts exist in a relatively low-oxygen (17.9 \pm (SD) $6.9 \mathrm{mmHg}$ ) environment (9) and most invasion is interstitial rather than endovascular. Over the next 4 weeks of gestation, extravillous trophoblast invade maternal spiral arterioles and are subjected to an increasing gradient of oxygenation. At 12-13 weeks of gestation, oxygen levels in the intervillous space rise to $60.7 \pm 8.5 \mathrm{mmHg}$, reflecting extravillous trophoblast remodeling of the spiral arterioles. It is likely that extravillous trophoblast displacing the endothelium of the spiral arterioles would experience arteriole oxygenation levels (95-100 mmHg). Therefore, the extravillous trophoblast invading along the endovascular pathway experience relatively higher oxygen levels than those undergoing interstitial decidual invasion. However the effect of high oxygen (hyperoxia) on first trimester trophoblast and its ability to regulate cell death is unknown.

Oxygen levels may have deleterious effects on the developing placenta and fetus, as studies from pregnancies at high altitude (10); more recently Levy et al. (11) demonstrated that exposure of term trophoblast to low oxygen tension induced apoptosis. Apoptosis is a crucial aspect for development because it permits a controlled decrease in cell number without directly alerting the immunologic system (12). Cellular debris is also preserved in a 
form that can be used by neighboring cells (13). There are at least two signaling pathways known to trigger apoptosis. The first is mediated by interactions of membrane receptors and ligands, such as Fas ligand. (14) The second pathway is triggered by exogenous stimuli such as radiation (15). The progression of the second or mitochondrial pathway occurs through dissipation of the mitochondrial membrane potential $\left(\psi_{\mathrm{m}}\right)$ followed by a cascade of intracellular proteases (caspases) (16). At present the mechanism by which trophoblast undergo apoptosis with respect to oxygen is unknown and this study aims to identify the pathway involved.

Apoptosis can be prevented in a number of different cell types by the action of several growth factors (17-19). Epidermal growth factor (EGF) was reported to prevent term trophoblast cell death (11) and regulate cytotrophoblast invasion (20); however, the initial signaling events of these processes have yet to be elucidated. An important intracellular mediator of anti-apoptotic effects is the phosphatidyl-inositol-3-kinase (PI3K) pathway acting through Akt to deactivate BAD and caspase-9, two important pro-apoptotic molecules. In a number of cell types, EGF was shown to signal through PI3K acting via Akt-mediated pathways (21-23). Furthermore, EGF may play a role in pregnancies complicated by fetal growth restriction and preeclampsia as it and its receptor were reported to be expressed at decreased levels (24-26).

This study set out to investigate the mechanism by which EGF prevented apoptosis and if EGF could affect oxygen-induced apoptosis within first trimester trophoblast cells. We report that dissipation of $\psi_{\mathrm{m}}$ occurs at all oxygen tensions, resulting in a statistically indistinguishable level of cell death. However, activation of caspases appears to occur more potently at oxygen tensions away from usual tissue oxygenation levels $\left(5 \% \mathrm{O}_{2}\right)$. In addition, inhibition of PI3K can sensitize the cells to oxygen-induced dissipation of $\psi_{\mathrm{m}}$. EGF can prevent this dissipation and restore cell viability independently of PI3K.

\section{Materials and Methods Materials}

Recombinant human EGF was purchased from Peprotech (London, UK) the PI3K inhibitor, LY294002, was purchased from Calbiochem (Nottingham, UK) and 3,3'-dihexyloxacarbocyanine $\left(\mathrm{DiOC}_{6}\right)$ from Molecular Probes (Cambridge Bioscience, Cambridge, UK). Anti-cleaved human caspase-3, -8, and -9 antibodies were purchased from Cell Signalling Technology (Herts, UK). Anti CD-133 was purchased from Miltenyi Biotech (Surrey, UK) and cytokeratin7 was purchased from Vector Laboratories (Peterborough, UK). All cell culture plastics were purchased from Triple Red (Thame, UK). All gas mixtures were purchased from Air Products (Crewe, UK). Poly Vinylidene Difluoride (PVDF) membranes and Enhanced Chemi Illuminescence (ECL) detection kits were purchased from AP Biotech (Bucks, UK). Nonfat milk was purchased from Premier Beverages (Staffs, UK). X-ray film was purchased from GRI (Essex, UK). All other reagents were obtained from Sigma (Poole, UK) unless otherwise stated.

\section{Cell Culture}

Spontaneously transformed first trimester human extravillous-like trophoblast $\left(\mathrm{ED}_{77}\right)$ were generated by repeated passaging of trophoblast obtained from chorionic villous sampling (27). These cells exhibit an extravillous trophoblast-like characteristic of cellular migration (28) and matrix metalloproteinase production (29) as well as expression of HLA-G, integrin $\beta 1$, and VCAM-1 (B. Bussolatti, personal communication). They were routinely cultured in $75 \mathrm{~cm}^{2}$ flasks in a 1:1 mixture of DMEM and Ham F-12 supplemented with $15 \%$ FCS, $2 \mathrm{mM}$ L-glutamine, $50 \mathrm{U} / \mathrm{ml}$ penicillin, and $50 \mu \mathrm{g} / \mathrm{ml}$ streptomycin. They were subcultured using sterile phosphate-buffered saline (PBS) and $1 \times$ Trypsin-EDTA when confluent and used up to passage number 65 . For experimental stimulations cells were cultured in $25 \mathrm{~cm}^{2}$ flasks. Cells were grown in these flasks until $70-80 \%$ confluence prior to experimental investigation.

\section{Cell Characterization by Flow Cytometry}

$\mathrm{ED}_{77}$ cells were routinely cultured and checked periodically for cell surface marker expression by flow cytometry. Briefly, $1 \times 10^{6}$ cells were collected by EDTA loosening, pelleted, and incubated for $1 \mathrm{hr}$ at $4^{\circ} \mathrm{C}$ with mouse anti-human HLA-G antibody (kindly provided by $\mathrm{O}$. Genbacev, University of California, San Francisco, CA, USA). Cells were washed three times in $1 \times$ PBS and incubated for $30 \mathrm{~min}$ at $4^{\circ} \mathrm{C}$ with anti-mouse FITC-conjugated secondary antibody. Cells were again washed three times in $1 \times$ PBS before being analyzed by flow cytometry.

The analysis of samples was performed using a FACS 440 flow cytometer (BD Bioscience, Oxford, UK) using an argon ion laser. An excitation wavelength of $488 \mathrm{~nm}$ was used with fluorescence emission measured at $530 \pm 15 \mathrm{~nm}$ through fluorescence channel 1 (FL1). A minimum of 10,000 cells per sample were collected using log amplification for FLl and linear amplification for forward light scanner and $90^{\circ}$ light scatter before being analyzed using inhouse software.

\section{Immunofluorescence}

$\mathrm{ED}_{77}$ were grown on 16-well glass chamber slides (VWR, Leics, UK) until 50\% confluent and fixed in ice-cold acetone. Slides were blocked in $10 \%$ normal goat serum (NGS) then incubated for $1 \mathrm{hr}$ at room temperature (RT) with mouse anti-human 
CD133 and cytokeratin-7 antibodies at 1:50 dilution in $10 \%$ NGS. Slides were washed three times in $1 \times$ PBS and incubated in the dark with 1:64 goat anti-mouse FITC-conjugated secondary antibody. Slides were again washed three times in $1 \times$ PBS and cover-slipped in $10 \% \mathrm{H}_{2} \mathrm{O}$ in glycerol. Visualization and image capture was performed using a fluorescent microscope (Nikon, Surrey, UK). Magnafire digital camera and Image Pro Plus software. (Data Cell, Berks, UK.)

\section{Measurement of $\psi m$ by Flow Cytometry}

Cells were incubated with $40 \mathrm{nM} \mathrm{DIOC}_{6}$ in $0.2 \%$ BSA DMEM:Ham F-12 (without phenol red) for 15 min and then washed three times with PBS. The PI3K inhibitor, LY294002, was incubated at the stated concentration for $30 \mathrm{~min}$. EGF or appropriate vehicle was given as a bolus after inhibitor incubation in a final volume of $2 \mathrm{ml}$. Flasks were then placed into the modular incubator chambers for the required time period with the correct atmospheric conditions as described below. At the end of the incubation, cells were removed from the chambers and all cells were harvested. Attached cells were detached using trypsin-EDTA and washed three times in PBS before addition of $3.75 \mu \mathrm{M}$ propidium iodide. Flow cytometry was performed as described, although fluorescence emission was measured at $530 \pm 15 \mathrm{~nm}$ through FLl and $620 \pm 20 \mathrm{~nm}$ through fluorescence channel 2 (FL2) for $\mathrm{DiOC}_{6}$ and propidium iodide, respectively. Owing to the emission spectrum of $\mathrm{DiOC}_{6}$, electronic compensation was used to correct for spillage of the $\mathrm{DiOC}_{6}$ (green, FL1) into the propidium iodide (red, FL2) channels. An intact $\psi_{m}$ was attributed to cells with a high fluorescence signal in FLl.

\section{Modular Incubator Chambers}

Tissue culture flasks containing near confluent cells were transferred to Modular Incubator chambers (ICN, Thame, Oxfordshire, UK) as described previously (8). In brief, the chambers were purged with nitrogen gas mixtures comprising of $1 \%, 5 \%$, or $21 \%$ (normal incubator conditions) oxygen supplemented with $5 \%$ carbon dioxide for $5 \mathrm{~min}$ then sealed for the duration of the experiment. At the end of the incubation, the pressure was released and flasks removed and analyzed accordingly.

\section{Measurement of Oxygen Tension Within Media}

An oxygen microelectrode was purchased from Microelectrodes Inc. (Bedford, NH, USA) and was calibrated by using gas mixtures of known values (1) $0 \% \mathrm{O}_{2}, 5 \% \mathrm{CO}_{2}, 95 \% \mathrm{~N}_{2}$ and (2) $40 \% \mathrm{O}_{2}, 5 \%$ $\mathrm{CO}_{2}, 55 \% \mathrm{~N}_{2}$. A standard $\mathrm{pH}$ meter (Mettler Toledo, Leics, UK) was used as the output device, once measurement signals had been transduced using an $\mathrm{O}_{2}$ adapter (Microelectrodes).

\section{Visual Assessment of Cellular Morphology}

Cell suspensions $(20 \mu \mathrm{l})$ from the experiments described above were removed prior to flow cytometry, placed on glass slides, cover slipped, and visualized using fluorescence microscopy (Nikon) to reveal cellular morphology. Images were captured as described.

\section{Western Blotting}

Proteins were extracted from trophoblast and subjected to Western blot analysis as previously described (30). Extracted protein $(50 \mu \mathrm{g})$ was resuspended in $2 \times$ sodium dodecyl sulfate (SDS) sample buffer and boiled for $5 \mathrm{~min}$. Proteins were separated on a $15 \%$ SDS-PAGE gel by electrophoresis and transferred to PVDF membranes at RT using a semi-dry transfer apparatus. Membranes were blocked with $10 \%$ low-fat milk in Tris-buffered saline with Tween (TBS-T) ( $10 \mathrm{mM}$ Tris [pH 7.5], $100 \mathrm{mM} \mathrm{NaCl}, 0.1 \%$ Tween 20) for $1 \mathrm{hr}$ at RT then washed three times for $10 \mathrm{~min}$ each in TBS-T at RT. Membranes were incubated with anticleaved caspase-3, caspase-8, or caspase- 9 antibody (1:1000) at $4^{\circ} \mathrm{C}$ overnight. Membranes were washed and incubated with appropriate horseradish peroxidase linked secondary antibody (Vector Labs, Peterborough, UK) for $1 \mathrm{hr}$ in $5 \%$ milk at room temperature. Antibody reactions were detected using the ECL detection kit, followed by detection of chemiluminescence on x-ray film.

\section{Statistical Analysis}

Analysis of differences between groups was performed using the Kruskal-Wallis nonparametric analysis of variance (ANOVA) test. A $p$ value of less than 0.05 was considered to be significantly different.

\section{Results}

Characterization of Extravillous Trophoblast Cell Line

At present, model trophoblast systems only exist for the latter stages of pregnancy $(31,32)$ when most of placental development has already occurred. In this study we report the characterization of a cell line, $\mathrm{ED}_{77}$, which exhibits many properties of in vivo trophoblast. Cells were analyzed for their expression of distinguishing cell surface marker proteins. Expression of HLA-G within human tissues is restricted to trophoblast and hence has become one of the most important identifying markers within these cells (33). Flow cytometry was used to determine the level of HLA-G present on these cells. Figure 1 (I) shows a representative histogram showing a marked increase in fluorescence of at least 20 -fold ( $\mathrm{ED}_{77}$ : heavy trace). The light trace shows the fluorescence pattern from a nonimmune control sample. We used immunofluorescence to identify the presence of other cell surface proteins. Figure 1 (II) shows expression of CD133, recently identified to be useful in characterizing 

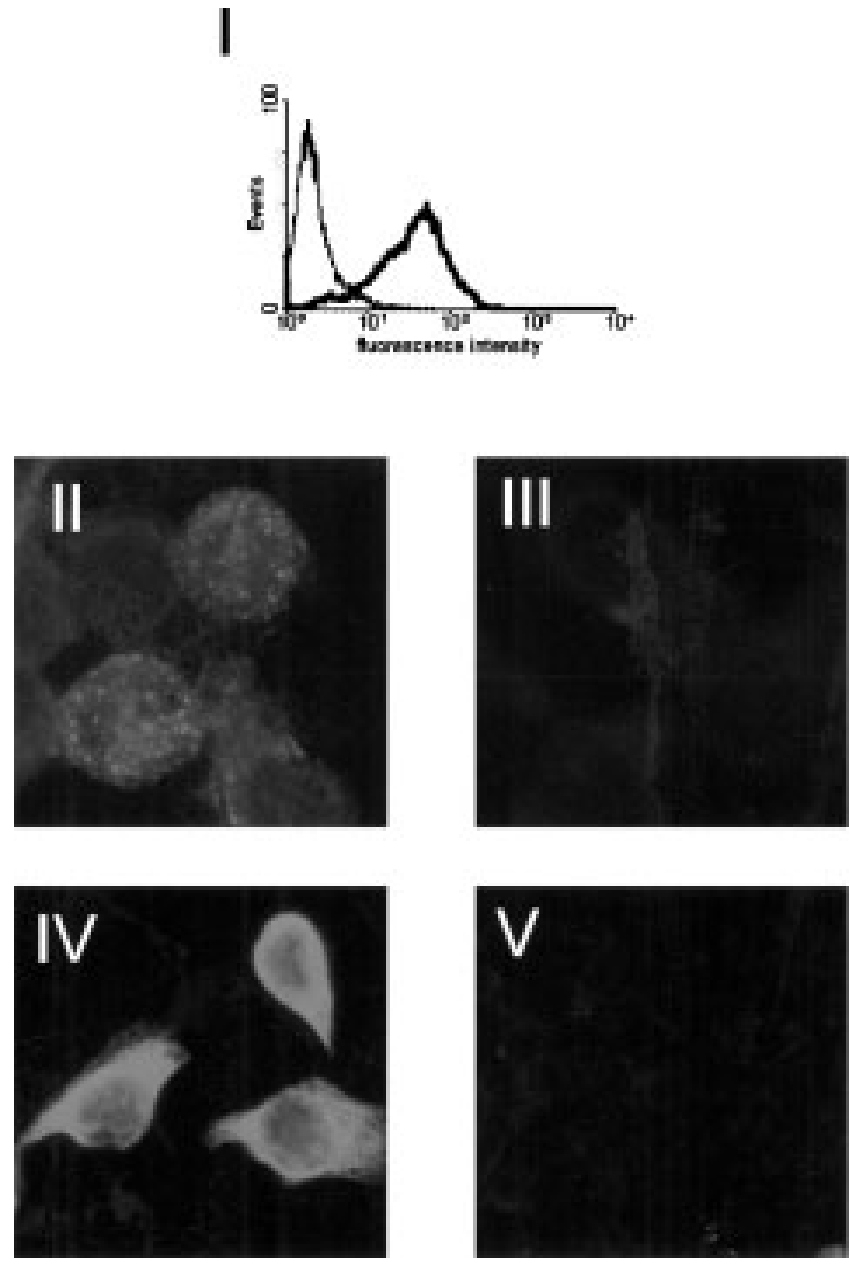

Fig. 1. Characterization of $\mathbf{E D}_{\mathbf{7 7}}$. (I) Flow cytometry analysis of HLA-G expression in $\mathrm{ED}_{77}$. A shift in fluorescence intensity is observed with $\mathrm{ED}_{77}$ (heavy trace) indicating expression of HLA-G as compared to nonimmune complex in control (light trace). Immunofluorescence for (II) Anti-CD 133 1:50 ED revealing a punctate expression pattern. (III) Control. (IV) Anti-cytokeratin-7 1:50 in $\mathrm{ED}_{77}$ showing strong widespread staining. (V) Control. (Original magnifications $\times 400$ ).

trophoblast (34) and Figure 1 (IV) shows abundant cytokeratin-7 expression and important structural protein within trophoblast (35). Figure 1 (III) and (VI) show corresponding controls for each antibody tested.

\section{Measurement of Dissolved $\mathrm{O}_{2}$ Within Incubation Culture Media}

An oxygen microelectrode was used to measure the oxygen tension within the media of the incubations and to determine if they were comparable to those that may occur in vivo. Table 1 shows measurements of incubations from $1 \%$ oxygen exogenous exposure showed a range of oxygen levels from 12.3-21.3 $\mathrm{mmHg}$, which is comparable to those levels measured in early pregnancy. Tissue normoxia or $5 \%$ oxygen exposure, as we have described it, resulted in oxygen levels of $50.2-64.3 \mathrm{mmHg}$, again comparable to oxygen levels at 12-13 weeks of gestation within the intervillous space (9). Finally, measurements from the $21 \%$ oxygen showed oxygenation levels in the range $106-133 \mathrm{mmHg}$, a close approximation for uterine arteriole oxygenation levels (approximately $100 \mathrm{mmHg}$ ). These chambers appear to maintain stable oxygenation levels throughout the incubations and the chosen gas mixes are appropriate for modeling the oxygenation levels that approximate to conditions in vivo.

\section{Trophoblast Cell Death Occurred Irrespective of Oxygen Tension}

Hypoxia was reported to induce apoptosis in trophoblast, but the effect of high oxygen tension and comparison to tissue normoxia $\left(5 \% \mathrm{O}_{2}\right)$ on trophoblast has not been assessed (11). A dual staining flow-cytometry method composed of $\mathrm{DiOC}_{6}$ and propidium iodide was used to ascertain whether the $\psi_{\mathrm{m}}$ was intact (live and healthy cell) or dissipated (dead cell). Surprisingly, all oxygen tensions tested induced a decrease in cell death to similar levels after $48 \mathrm{hr}$ (Fig. 2). The representative raw dot-plot data from $21 \% \mathrm{O}_{2}$ (Fig. 2A) incubation shows a gradual decrease over time in the proportion of live cells $\left(\mathrm{DIOC}_{6}+\mathrm{ve}\right.$, Propidium Iodide -ve) from quadrant $\mathrm{I}$ and increase through quadrant III $\left(\mathrm{DIOC}_{6}-\mathrm{ve}\right.$, propidium iodide - ve) to quadrant IV $\left(\right.$ DIOC $_{6}-$ ve, Propidium Iodide + ve) by $48 \mathrm{hr}$. The level of cells with dissipated $\psi_{\mathrm{m}}$ increased sufficiently over time to reach statistical significance at $1 \%$ and $21 \% \mathrm{O}_{2}$ as compared to levels after $12 \mathrm{hr}$. However, when comparing between oxygen tensions at the same time point, the levels of $\psi_{\mathrm{m}}$ were statistically indistinguishable. Having found no difference in the change in $\psi_{\mathrm{m}}$ we went on to investigate whether activation of downstream initiator (caspase-9) or effector (Caspase-3) occurred in similar manner.

\section{Determination of Caspase Activation}

Caspases, once cleaved and activated, play an important role in the molecular progression of apoptosis. (36) After 24-hr exposure to the oxygen tensions tested, there were detectable levels of cleaved caspase- 3 and caspase- 9 fragment by Western blot. In divergence with the $\psi_{\mathrm{m}}$ data, we found that a change in the oxygen tension away from tissue normoxia $\left(5 \% \mathrm{O}_{2}\right)$, induced marked increases in expression of active caspase-9 and caspase-3 fragments. Interestingly, we were unable to find any expression of active caspase- 8 fragment (data not shown), which may indicate that the mechanism of apoptosis was primarily through the mitochondria.

\section{Morphologic Analysis}

Cells undergoing apoptosis exhibit distinct morphologic changes compared to live cells and it is 
Table 1. Dissolved oxygen levels determined in media from modular incubator chamber experiments

\begin{tabular}{|c|c|c|c|c|c|c|}
\hline $\begin{array}{l}\text { Oxygen } \\
\text { Tension in } \\
\text { Chamber }\end{array}$ & Time (h) & Range mmHg & Mean mmHg & Median & SD & $n$ \\
\hline $1 \%$ & $\begin{array}{l}12 \\
24 \\
48\end{array}$ & $\begin{array}{l}12.3-21.3 \\
13.2-19.2 \\
12.8-19.6\end{array}$ & $\begin{array}{l}16.7 \\
16.3 \\
15.5\end{array}$ & $\begin{array}{l}16.8 \\
16.2 \\
16.2\end{array}$ & $\begin{array}{l}3.46 \\
2.52 \\
2.56\end{array}$ & $\begin{array}{l}6 \\
6 \\
6\end{array}$ \\
\hline $5 \%$ & $\begin{array}{l}12 \\
24 \\
48\end{array}$ & $\begin{array}{l}50.2-63.4 \\
57.0-62.6 \\
56.2-64.3\end{array}$ & $\begin{array}{l}57.0 \\
59.9 \\
60.4\end{array}$ & $\begin{array}{l}56.8 \\
59.8 \\
60.2\end{array}$ & $\begin{array}{l}4.61 \\
1.88 \\
3.00\end{array}$ & $\begin{array}{l}6 \\
6 \\
6\end{array}$ \\
\hline $21 \%$ & $\begin{array}{l}12 \\
24 \\
48\end{array}$ & $\begin{array}{l}106.0-133.0 \\
109.0-124.0 \\
107.0-124.0\end{array}$ & $\begin{array}{l}117.0 \\
116.0 \\
114.0\end{array}$ & $\begin{array}{l}119 \\
116 \\
115\end{array}$ & $\begin{array}{l}9.10 \\
5.30 \\
6.90\end{array}$ & $\begin{array}{l}6 \\
6 \\
6\end{array}$ \\
\hline
\end{tabular}

still recognized that a definitive assessment of an apoptotic cell is through direct visualization and morphologic analysis. Our study used a proportion of cell suspensions from the flow cytometry experiments to demonstrate the presence of cells undergoing apoptosis. Visualized cellular damage from $1 \% \mathrm{O}_{2}$ is shown from a representative field from fluorescence microscopy morphologic analysis at the time points stated (Fig. 2F). The $\mathrm{DiOC}_{6}$ compound sequesters in the mitochondria of live cells (Fig. 2F panels I and IV), whereas in nonviable cells, the mitochondrial membrane becomes permeabilized and $\mathrm{DiOC}_{6}$ is lost from the mitochondria and becomes diffuse within the cytoplasm. Further progression through the cell death pathway results in plasma membrane rupture and influx of the
DNA binding compound propidium iodide that stains the cells orange/red. The abundance of fluorescent orange and red cells increased over time while the green fluorescence is reduced indicating an increase in cell death (Fig. 2F panels I-III). Analysis of individual cells under high magnification at different stages of apoptosis is depicted in Figure 2F (panels IV and V). Localized DiOC 6 sequestration within mitochondria indicates a live cell (Fig. 2F panel IV), and a cell during apoptosis shows distinct apoptotic blebs and condensation of nuclear DNA (Fig. 2F panel V).

\section{Effect of PI3K Inhibitor on $\psi \mathrm{m}$ and Cleavage of Caspase-3}

The selective PI3K inhibitor LY294002 was used to disrupt signaling through the PI3K pathway.

A

$12 \mathrm{~h}$

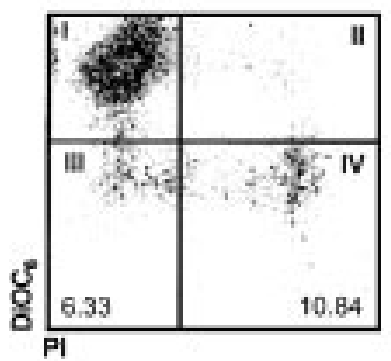

$24 \mathrm{~h}$

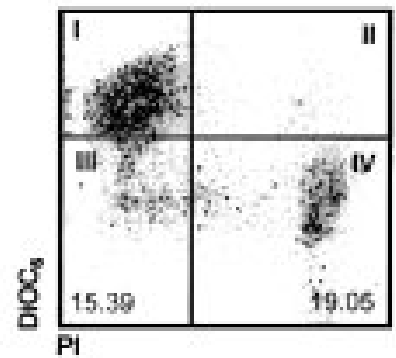

$48 \mathrm{~h}$

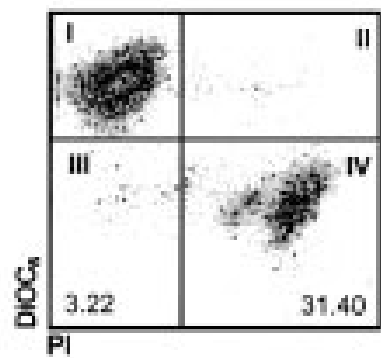

Fig. 2. Time-dependent increase in cell death, cleavage of caspase and visual assessment of cell death. Cell viability with $\mathrm{ED}_{77}$ cells over time with differing oxygen concentrations was measured at $1 \% \mathrm{O}_{2}(\mathbf{B}), 5 \% \mathrm{O}_{2}(\mathrm{C})$, and $21 \% \mathrm{O}_{2}(\mathrm{~A}, \mathrm{D})$. (A) Representative raw data plot for $21 \% \mathrm{O}_{2}$ incubation at different durations. Cells were incubated for the times stated under the oxygen tensions indicated in the figure. Hatched shaded bars represent cells with intact $\Psi_{\mathrm{m}}$ (live cells); darkly shaded bars represent cells with dissipated $\Psi_{\mathrm{m}}$ (dead cells). Minimum $n=3$ Error bars are \pm SEM. (B) * $p<0.05$ versus $12 \mathrm{hr}$ (intact); $+p<0.0512 \mathrm{hr}$ (dissipated). (C) Difference in all test groups did not reach statistical significance. (D) Difference in all test groups did not reach statistical significance. (E) First trimester trophoblast exposed to $1 \%, 5 \%$, and $21 \%$ for the time periods shown. Cell lysates were prepared in RIPA and equal amounts $(50 \mu \mathrm{g})$ of protein were separated by SDS-PAGE, transferred to PVDF membrane, and probed with antibodies to the cleaved active form of caspase-3 and caspase-9. Similar results were obtained in two separate experiments. (F) Cells were loaded with $\mathrm{DIOC}_{6}$, exposed to $21 \% \mathrm{O}_{2}$ for the time specified in the figure then stained with propidium iodide and were placed on chamber slides and visualized using Nikon fluorescence microscope. (I) $12 \mathrm{hr}$; (II) $24 \mathrm{hr}$; (III) $48 \mathrm{hr}$. Original magnifications $\times 100$. (IV) Individual live trophoblast. (V) Trophoblast undergoing apoptosis. Original magnifications $\times 400$. 
B

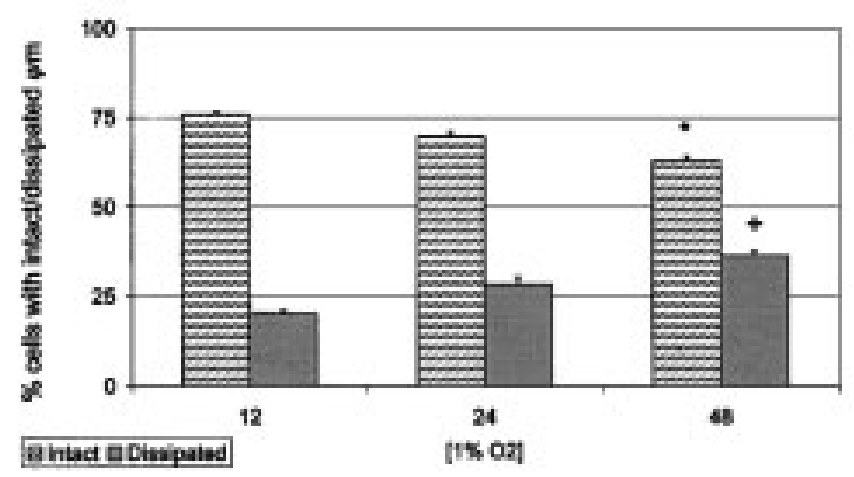

C

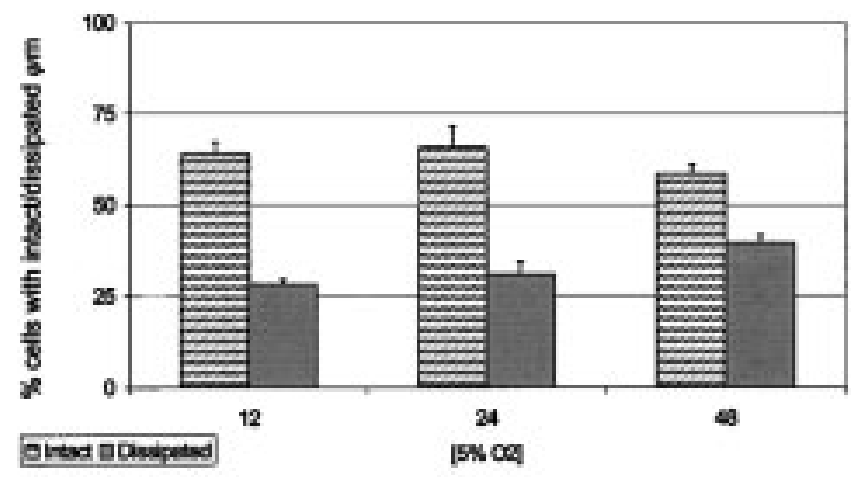

D

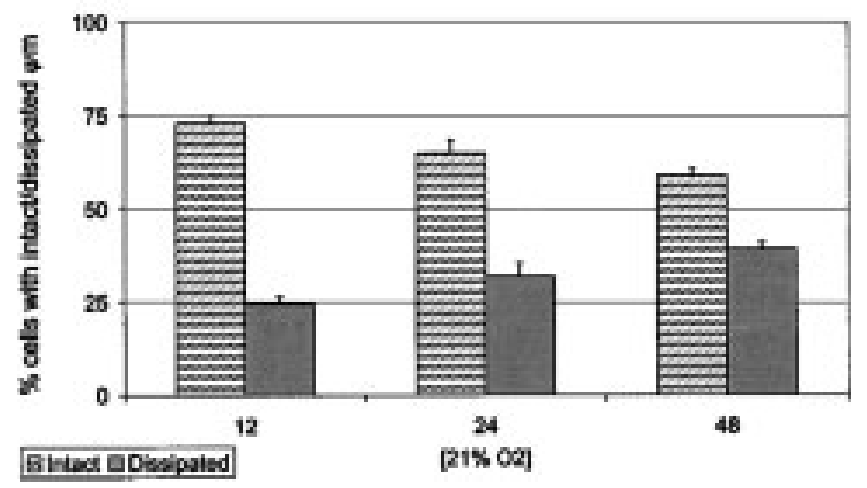

Fig. 2. (Continued)

Initially, a dose response for this compound was performed to determine the optimum concentration for future experiments. Incubation with increasing concentrations of LY294002 caused an increase in the dissipation of $\psi_{\mathrm{m}}$ as shown by the decrease in live cells (hatched bars) and corresponding increase in dead cells (solid bars) (Fig. 3A). Only at $40 \mu \mathrm{M}$ was a significant decrease measurable and so this concentration was used in subsequent experiments. The effect of LY294002 (40 $\mu \mathrm{M})$ on $\psi_{\mathrm{m}}$ was assessed after $24 \mathrm{hr}$ incubation at $1 \%$, $5 \%$, and $21 \%$ oxygen tension. The raw data plot
E

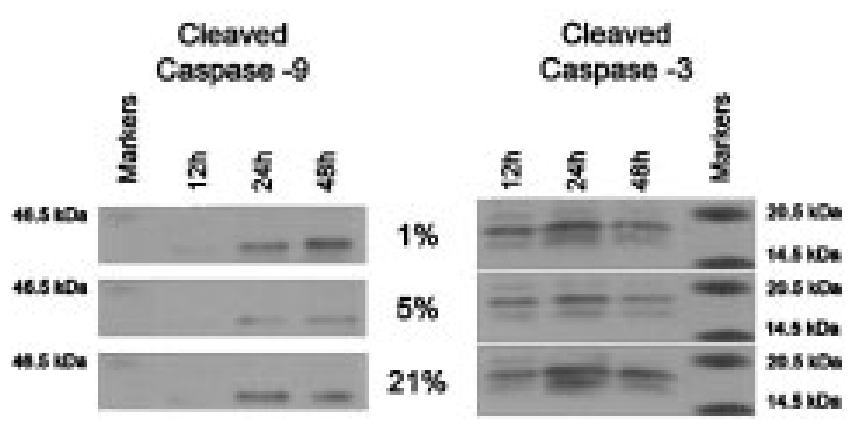

F

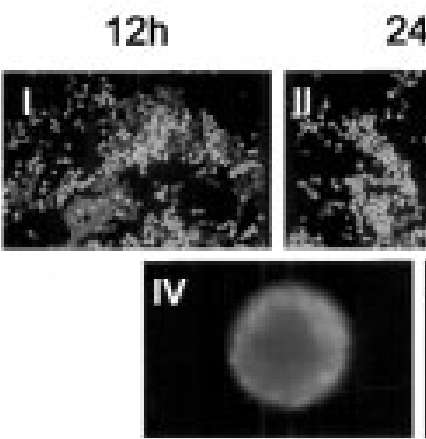

Live

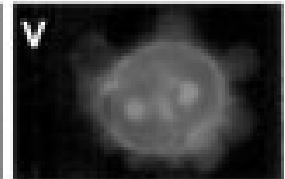

Apoptotic from 10,000 collected cells (Fig. 3B) shows a dramatic decrease in the proportion of live cells $\left(\right.$ DIOC $_{6}+$ ve, propidium iodide - ve [quadrant I]) when incubated with LY294002. However, the increase in $\psi_{\mathrm{m}}$ dissipation with LY294002 was not as dramatic at $21 \% \mathrm{O}_{2}$ (Fig. 3E) as compared to $1 \% \mathrm{O}_{2}$ (Fig. 3C) or $5 \% \mathrm{O}_{2}$ (Fig. 3D). When EGF $(10 \mathrm{ng} / \mathrm{ml}$ ) was added in conjunction with LY294002, it could reverse the inhibitory effect of LY294002 at all oxygen concentrations tested (Fig. 3C, $3 \mathrm{D}, 3 \mathrm{E})$ and reached statistical significance at $1 \%(p<0.01, n=11$; Fig. $3 \mathrm{C})$ as well as $21 \% \mathrm{O}_{2}$ 
A

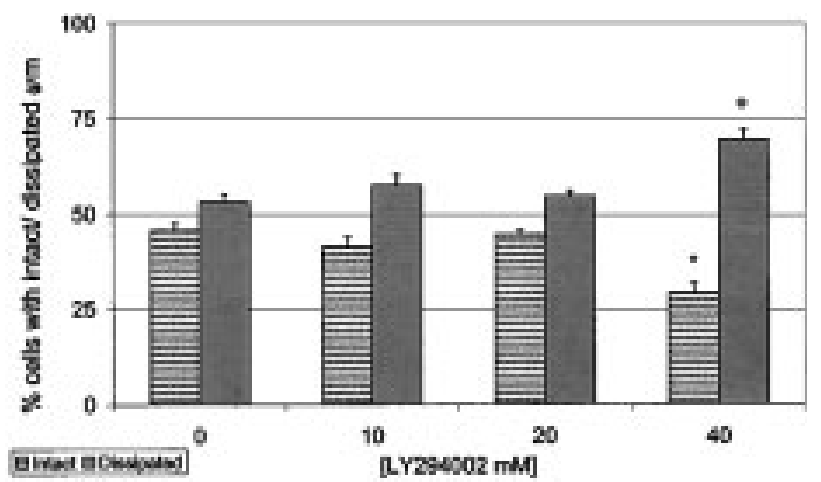

B

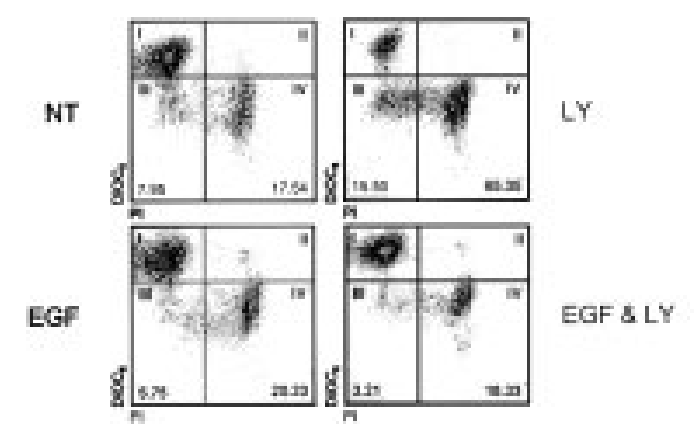

C

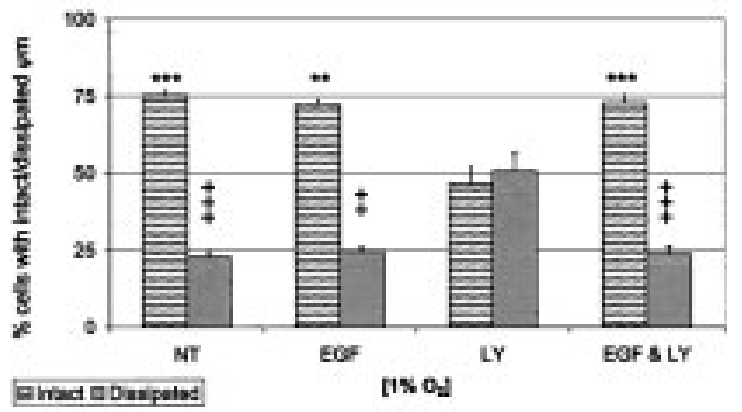

D

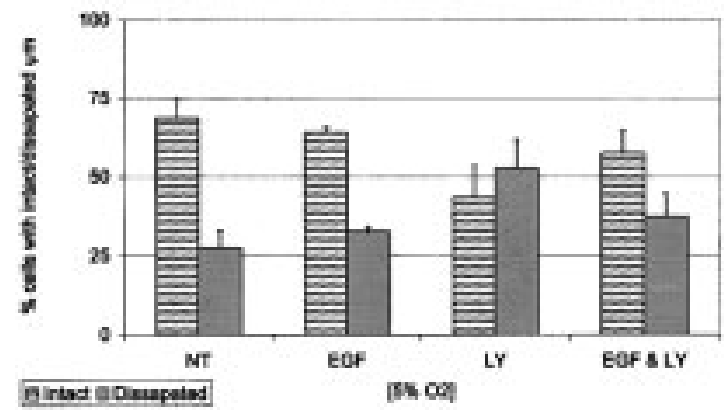

E

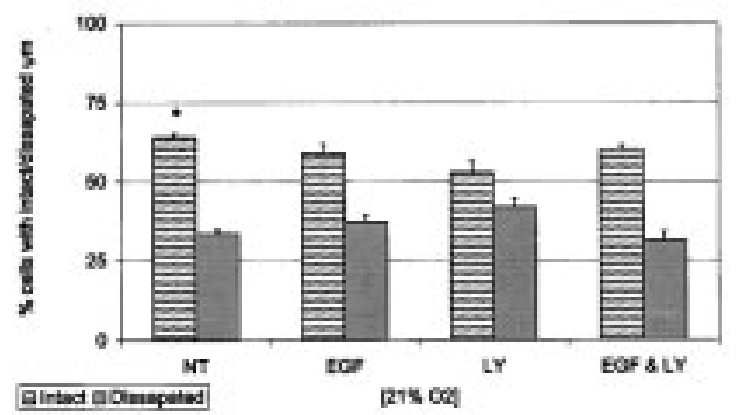

F

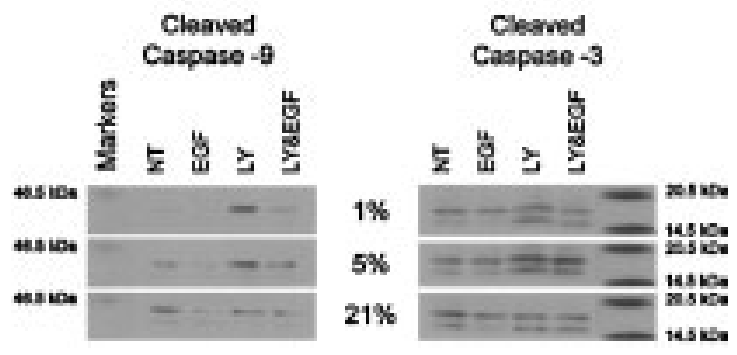

Fig. 3. Effect of LY294002 and EGF on mitochondrial membrane potential, cleaved caspase-3 status, and morphology after $24 \mathrm{hr}$ at differing oxygen concentrations. $\mathrm{ED}_{77}$ cells exposed to $1 \%, 5 \%$, or $21 \%$ oxygen for $24 \mathrm{hr}$ with and without EGF or LY294002. (A) Dose response for LY294002 after $48 \mathrm{hr}$ incubation. Hatched shaded bars represent cells with intact $\psi_{\mathrm{m}}$ (live cells); darkly shaded bars represent cells with dissipated $\psi_{\mathrm{m}}$ (dead cells). Minimum $n=6$. Error bars are \pm SEM. * $p<0.05$ versus NT (intact); $+p<0.05$ versus NT (dissipated). (B) Representative raw data plot for $1 \% \mathrm{O}_{2} 24 \mathrm{hr}$ incubation \pm EGF or LY. NT, no treatment; EGF, EGF $10 \mathrm{ng} / \mathrm{ml}$; LY, LY294002 $40 \mu \mathrm{M}$; E+L, EGF $10 \mathrm{ng} / \mathrm{ml}$ plus LY294002 $40 \mu \mathrm{M}$. (C,D,E) Cells were incubated for $24 \mathrm{hr}$ under the oxygen tensions indicated. (C) ${ }^{* * *} p<0.001$ versus LY (intact); ${ }^{* *} p<0.01$ versus LY (intact); $+++p<0.001$ versus LY (dissipated); $++p<0.01$ versus LY (dissipated). (D) Difference in all test groups did not reach statistical significance. (E) * $p<0.05$ versus LY (intact). (F) First trimester trophoblast cells were exposed to $1 \%, 5 \%$, and $21 \%$ oxygen for $24 \mathrm{hr}$. Cell lysates were prepared in RIPA and $50 \mu \mathrm{g}$ protein were separated by SDS-PAGE, transferred to PVDF membrane, and probed with antibodies to the cleaved, active form of caspase-3 and caspase-9. Similar results were obtained in two separate experiments. NT, no treatment; EGF, EGF 10 ng/ml;

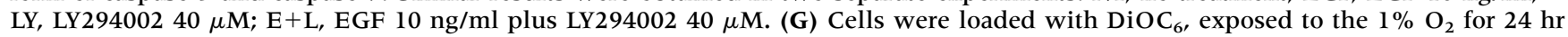
then stained again with propidium iodide and were placed on chamber slides and visualized using Nikon fluorescence microscope. (I) NT, no treatment. (II) EGF, EGF 10 ng/ml. (III) LY, LY294002 $40 \mu \mathrm{M}$. (IV) E+L = EGF 10 ng/ml plus LY294002 $40 \mu \mathrm{M}$. Original magnifications $\times 100$. (V) Individual live trophoblast. (VI) Trophoblast undergoing apoptosis. Original magnifications $\times 400$.

$(p<0.05, n=8$; Fig. 3E). Initially, EGF was used at both $100 \mathrm{ng} / \mathrm{ml}$ (data not shown) and $10 \mathrm{ng} / \mathrm{ml}$, but because the lower concentration had a similar effect, subsequent experiments were conducted using the lower concentration. EGF had no effect on oxygen-induced cell death itself and could not prevent dissipation of $\psi_{\mathrm{m}}$ in trophoblast at these oxygen tensions (Fig. 3C, 3D, 3E). 
G

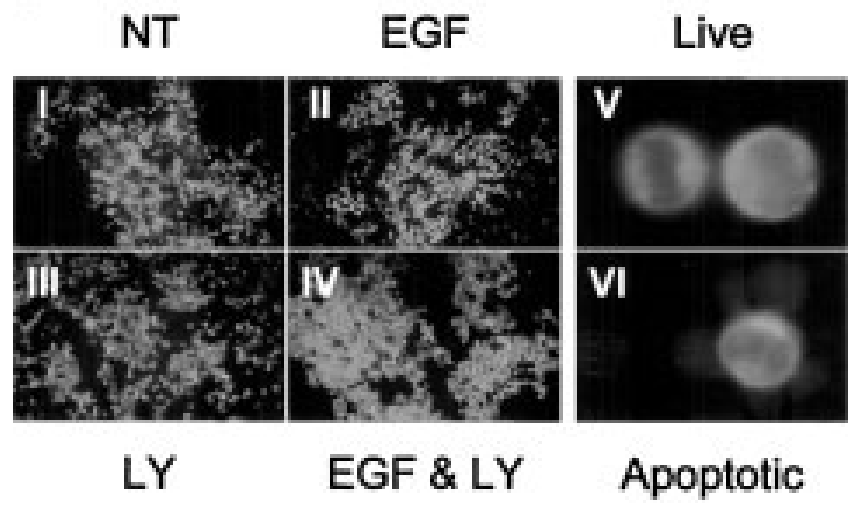

Fig. 3. (Continued)

\section{Effect of LY and EGF on Caspase Cleavage}

Incubation with LY294002 (LY) increased cleaved caspase-3 and caspase-9 levels (Fig. 3F). In concurrence with the flow cytometry data, LY induced caspase- 3 and caspase-9 cleavage was inhibited when EGF was incubated in conjunction with LY294002 (EGF plus LY). (Fig. 3F). At 1\% oxygen, EGF alone (EGF) did not alter the levels of active cleaved caspase-3 fragment as compared to untreated cells but at higher oxygen tensions, EGF prevented caspase3 and caspase- 9 cleavage. Morphologic assessment of these cells was performed to determine if apoptotic morphology was present, as shown in Figure 3G. Incubation with LY294002 caused a decrease numbers of live cells $\left(\mathrm{DiOC}_{6}\right.$ positive green stain; Fig. 3G panel III), and an increase in the numbers of dying/dead cells (propidium iodide positive stain; [orange/red]). EGF (10 ng/ml) prevented cell death and maintained the live cell population even in the presence of LY294002 (Fig. 3G panel IV).

\section{Discussion}

Although hypoxia is known to induce apoptosis in a number of cell types (37-39), the mechanism by which it induces apoptosis in trophoblast is unknown. (11). This study demonstrates that hyperoxia $\left(21 \% \mathrm{O}_{2}\right)$ as well as hypoxia $\left(1 \% \mathrm{O}_{2}\right)$ affects cleavage of caspases. It also for the first time shows that inhibition of the PI3K pathway in trophoblast increases the dissipation of the $\psi_{\mathrm{m}}$, one of the earliest markers of apoptosis. The increase in trophoblast death induced by oxygen or inhibition of the PI3K correlated with an increase in the cleavage of caspase-3 and caspase-9. EGF was able to maintain both $\psi_{\mathrm{m}}$ and prevent cleavage of caspase- 3 in the presence or absence of PI3K inhibitor under different oxygen tensions. This finding is supported by a recent study demonstrating that EGF prevents LY294002-induced apoptosis and reduces capase-3 activity in the prostate cancer cell line LNCaP (40). However, the current work is the first example demonstrating that EGF action is independent of PI3K/Akt pathway in noncarcinoma cells. Because we were unable to detect an increase in the cleaved form of caspase-8, we speculate that the ligandbased pathway was unlikely to be involved and apoptosis is more likely to be under complete control of the mitochondrion. These results suggest a common mechanism for induction of apoptosis by altered oxygen tension or inhibition of PI3K that involves activation of caspase- 3 predominantly through caspase-9 via the mitochondrial pathway.

The significance of the PI3K pathway is important; we demonstrate that if it is blocked, increased cell death occurs. Any defect in PI3K signaling, such as through a genetic mutation or a natural inhibitor, may sensitize a proportion of the trophoblast population to oxygen-induced cell death. This would be most apparent under conditions of lower oxygen tension where the PI3K pathway may be usually active to aid trophoblast survival within the low oxygen environment. We have used $40 \mu \mathrm{M}$ LY294002, although a relatively high concentration, it has been used in other studies (41-43), and was the lowest concentration to cause a decrease in $\psi_{\mathrm{m}}$. The greatest decrease in live cells was observed when the PI3K pathway was blocked under conditions of hypoxia or normoxia. This may indicate that the PI3K pathway could be important in regulating cell survival signaling in first trimester trophoblast during in the first weeks of pregnancy before the invasion of the spiral arteries and establishment of a regular blood flow to the placenta. Under hyperoxic $\left(21 \% \mathrm{O}_{2}\right)$ conditions, blockade of the PI3K pathway caused only a slight increase in dissipation of $\psi_{\mathrm{m}}$, suggesting that under these conditions other survival pathways may compensate for PI3K.

This study was performed using the first trimester trophoblast-like cell line $\mathrm{ED}_{77}$ and we have demonstrated that it exhibits trophoblast-like behavior and expression of trophoblast specific markers. It is still, however, a transformed cell line that can only model in vivo cell function. It is known that some transformed cell lines have altered cell death regulation pathways, but this study is the first to demonstrate expression and activation of caspases in trophoblast-like cells. These cells may go someway towards understanding the mechanism of oxygeninduced cell death in preeclampsia, which has been hypothesized to be caused by the changing level of oxygenation within the first few weeks of gestation. $(44,45)$. What may be occurring in preeclampsia is a hypoxia-reperfusion type insult that affects the functionality of the syncytio/cytotrophoblast bilayer. Due to the nonproliferative capacity of primary culture first trimester trophoblast, there have been relatively few studies of trophoblast intracellular survival mechanisms. We believe the $\mathrm{ED}_{77}$ cells are a useful model to investigate signaling mechanisms and are a guide to what may be occurring in vivo. These experiments would need to be repeated on first trimester tissue to validate our hypothesis. 
We have demonstrated that EGF cannot prevent oxygen-induced cell death per se, but can act to maintain trophoblast viability under conditions of compromised intracellular signaling. Our finding that EGF could prevent LY-induced cell death at a concentration of $10 \mathrm{ng} / \mathrm{ml}$ supports previous evidence that this growth factor is important for trophoblast function $(46,47)$. In addition, prevention of cell death by EGF occurred with the use of $40 \mu \mathrm{M}$ of LY294002, which emphasizes the PI3K-independent nature of the action of EGF. EGF may also be involved in aspects of placental pathology as EGF levels in maternal urine during early gestation may be a possible predictor of intrauterine growth restriction (25). If the maternal urine EGF levels correlate with local EGF levels within the placenta, then a decrease in EGF levels during the first trimester of pregnancy may have a dramatic effect on trophoblast function. A combination of intracellular signaling irregularities and low EGF levels may prevent the action of survival signals that act to ensure correct trophoblast invasion and establishment of a full and functional blood supply takes place.

Although no difference in $\psi_{\mathrm{m}}$ dissipation could be measured when cells are exposed to EGF alone compared to untreated cells, differences in caspase activation were detectable under the same conditions. It is important to note that although measuring $\psi_{\mathrm{m}}$ by $\mathrm{DiOC}_{6}$ and propidium iodide staining is a useful parameter in identifying apoptotic progression, the assay may not distinguish relatively small changes in apoptosis that are revealed by the caspase assay. To obtain an overall apoptotic picture, the flow cytometry assay must be used in conjunction with other techniques to determine the extent of apoptosis within a population.

In summary, this study demonstrates that first trimester extravillous-like trophoblast possess apoptotic machinery that can be induced by alteration in oxygen tension or inhibition of PI3K pathway via the mitochondrial-based pathway. It also shows that if oxygen tensions deviate from normoxia, then initiator and executor caspases can be activated in first trimester extravillous-like trophoblast cells. Finally, this study shows that although EGF cannot prevent oxygen-induced cell death per se, it is able to maintain both $\psi_{\mathrm{m}}$ and prevent cleavage of caspase- 3 in the presence or absence of PI3K inhibitor, suggesting that EGF promotes cell survival independent of PI3K in this extravillous-like trophoblast cell line.

\section{Acknowledgments}

We are grateful to Dr D.A. Kniss (Ohio State University, Columbus, Ohio, USA) for the generous gift of spontaneously transformed trophoblast cell lines. Thanks also go to Dr O. Genbacev (California, USA) for provision of the anti-HLA-G antibody for characterization studies. We greatly appreciate the assistance with immunofluorescence ( $\mathrm{Dr}$ B. Bussolati, Turin, Italy) and flow cytometry (Dr M Rahman, Birmingham, UK, and Mr. R. Bird, IDRL Birmingham, UK).

This work was funded by the British Heart Foundation Grant Numbers FS/1998079 and RG/98/0003.

\section{References}

1. Damsky CH, Fitzgerald ML, Fisher SJ. (1992) Distribution patterns of extracellular matrix components and adhesion receptors are intricately modulated during first trimester cytotrophoblast differentiation along the invasive pathway, in vivo. J. Clin. Invest. 89: 210-222.

2. Cross JC, Werb Z, Fisher SJ. (1994) Implantation and the placenta: key pieces of the development puzzle. Science 266: 1508-1518.

3. Aplin JD: (1991) Implantation, trophoblast differentiation and haemochorial placentation: mechanistic evidence in vivo and in vitro. J. Cell Sci. 1991. 99: 681-692.

4. Levine RJ, Hauth JC, Curet LB, et al. (1997) Trial of calcium to prevent preeclampsia. N. Engl. J. Med. 337: 69-76.

5. Zhou Y, Damsky CH, Chiu K, et al. (1993) Preeclampsia is associated with abnormal expression of adhesion molecules by invasive cytotrophoblasts. J. Clin. Invest. 91: 950-960.

6. Caniggia I, Grisaru-Gravnosky S, Kuliszewsky M, et al. (1999) Inhibition of TGF-beta 3 restores the invasive capability of extravillous trophoblasts in preeclamptic pregnancies. J. Clin. Invest. 103: 1641-1650.

7. Benirschke K, Kaufmann P: Pathology of the Human Placenta, 3rd ed. Springer-Verlag, New York; 1995.

8. Khaliq A, Dunk C, Jiang J, et al. (1999) Hypoxia downregulates placenta growth factor, whereas fetal growth restriction up-regulates placenta growth factor expression: molecular evidence for "placental hyperoxia" in intrauterine growth restriction. Lab. Invest. 79: 151-170.

9. Rodesch F, Simon P, Donner C, Jauniaux E. (1992) Oxygen measurements in endometrial and trophoblastic tissues during early pregnancy. Obstet. Gynecol. 80: 283-285.

10. Espinoza J, Sebire NJ, McAuliffe F, et al. (2001) Placental villus morphology in relation to maternal hypoxia at high altitude. Placenta 22: 606-608.

11. Levy R, Smith SD, Chandler K, et al. (2000) Apoptosis in human cultured trophoblasts is enhanced by hypoxia and diminished by epidermal growth factor. Am. J. Physiol. Cell Physiol. 278: C982-C988.

12. Kerr JF, Wyllie AH, Currie AR. (1972) Apoptosis: a basic biological phenomenon with wide-ranging implications in tissue kinetics. Br. J. Cancer 26: 239-257.

13. Messmer UK, Pfeilschifter J. (2000) New insights into the mechanism for clearance of apoptotic cells. Bioessays 22: 878-881.

14. Schneider P, Tschopp J. (2000) Apoptosis induced by death receptors. Pharm. Acta Helv. 74: 281-286.

15. Zimmermann KC, Bonzon C, Green DR. (2001) The machinery of programmed cell death. Pharmacol. Ther. 92: 57-70.

16. Thornberry NA, Lazebnik Y. (1998) Caspases: enemies within. Science 281: 1312-1316.

17. Rosfjord EC, Dickson RB. (1999) Growth factors, apoptosis, and survival of mammary epithelial cells. J. Mammary Gland Biol. Neoplasia 4: 229-237.

18. Liu W, Ahmad SA, Reinmuth N, et al. (2000) Endothelial cell survival and apoptosis in the tumor vasculature. Apoptosis 5: $323-328$.

19. Kamata H, Tanaka C, Yagisawa H, Hirata H. (1996) Nerve growth factor and forskolin prevent $\mathrm{H} 2 \mathrm{O} 2$-induced apoptosis in PC12 cells by glutathione independent mechanism. Neurosci. Lett. 212: 179-182.

20. Bass KE, Morrish D, Roth I, et al. (1994) Human cytotrophoblast invasion is up-regulated by epidermal growth factor: evidence that paracrine factors modify this process. Dev. Biol. 164: 550-561.

21. Zubilewicz A, Hecquet C, Jeanny J, et al. (2001) Proliferation of CECs requires dual signaling through both MAPK/ERK 
and PI 3-K/Akt pathways. Invest. Ophthalmol. Vis. Sci. 42: $488-496$.

22. Xie H, Pallero MA, Gupta K, et al. (1998) EGF receptor regulation of cell motility: EGF induces disassembly of focal adhesions independently of the motility-associated PLCgamma signaling pathway. J. Cell Sci. 111: 615-624.

23. Roberts RA, James NH, Cosulich SC. (2000) The role of protein kinase $\mathrm{B}$ and mitogen-activated protein kinase in epidermal growth factor and tumor necrosis factor alphamediated rat hepatocyte survival and apoptosis. Hepatology 31: 420-427.

24. Varner MW, Dildy GA, Hunter C, et al. (1996) Amniotic fluid epidermal growth factor levels in normal and abnormal pregnancies. J. Soc. Gynecol. Investig. 3: 17-19.

25. Lindqvist P, Grennert L, Marsal K. (1999) Epidermal growth factor in maternal urine-a predictor of intrauterine growth restriction? Early Hum. Dev. 56: 143-150.

26. Faxen M, Nasiell J, Blanck A, et al. (1998) Altered mRNA expression pattern of placental epidermal growth factor receptor (EGFR) in pregnancies complicated by preeclampsia and/or intrauterine growth retardation. Am. J. Perinatol. 15: 9-13.

27. Diss EM, Gabbe SG, Moore JW, Kniss DA. (1992) Study of thromboxane and prostacyclin metabolism in an in vitro model of first-trimester human trophoblast. Am. J. Obstet. Gynecol. 167: 1046-1052.

28. Dunk C, Shams M, Nijjar S, et al. (2000) Angiopoietin-1 and angiopoietin-2 activate trophoblast Tie-2 to promote growth and migration during placental development. Am. J. Pathol. 156: $2185-2199$.

29. Morgan M, Kniss D, McDonnell S. (1998) Expression of metalloproteinases and their inhibitors in human trophoblast continuous cell lines. Exp. Cell Res. 242: 18-26.

30. Khaliq A, Li XF, Shams M, et al. (1996) Localisation of placenta growth factor (PIGF) in human term placenta. Growth Factors 13: 243-250.

31. Bahn RS, Worsham A, Speeg Jr KV, et al. (1981) Characterization of steroid production in cultured human choriocarcinoma cells. J. Clin. Endocrinol. Metab. 52: 447-450.

32. Hunt JS, Andrews GK, Wood GW. (1987) Normal trophoblasts resist induction of class I HLA. J. Immunol. 138: 2481-2487.

33. McMaster MT, Librach CL, Zhou Y, et al. (1995) Human placental HLA-G expression is restricted to differentiated cytotrophoblasts. J. Immunol. 154: 3771-3778.

34. Potgens AJ, Bolte M, Huppertz B, et al. (2001) Human trophoblast contains an intracellular protein reactive with an antibody against CD133-a novel marker for trophoblast. Placenta 22: 639-645.

35. Blaschitz A, Weiss U, Dohr G, Desoye G. (2000) Antibody reaction patterns in first trimester placenta: implications for trophoblast isolation and purity screening. Placenta 21: 733-741.

36. Shi Y. (2002) Mechanisms of caspase activation and inhibition during apoptosis. Mol. Cell. 9: 459-470.

37. Muschel RJ, Bernhard EJ, Garza L, et al. (1995) Induction of apoptosis at different oxygen tensions: evidence that oxygen radicals do not mediate apoptotic signaling. Cancer Res. 55: 995-998.

38. Graeber TG, Osmanian C, Jacks T, et al. (1996) Hypoxiamediated selection of cells with diminished apoptotic potential in solid tumours. Nature 379: 88-91.

39. Banasiak KJ, Haddad GG. (1998) Hypoxia-induced apoptosis: effect of hypoxic severity and role of p53 in neuronal cell death. Brain Res. 797: 295-304.

40. Carson JP, Kulik G, Weber MJ. (1999) Antiapoptotic signaling in LNCaP prostate cancer cells: a survival signaling pathway independent of phosphatidylinositol 3'-kinase and Akt/protein kinase B. Cancer Res. 59: 1449-1453.

41. Hirasawa N, Sato Y, Fujita Y, Mue S, Ohuchi K. (1998) Inhibition by dexamethasone of antigen-induced c-Jun $\mathrm{N}$-terminal kinase activation in rat basophilic leukemia cells. J. Immunol. 161: 4939-4943.

42. Rameh LE, Rhee SG, Spokes K, et al. (1998) Phosphoinositide 3-kinase regulates phospholipase Cgamma-mediated calcium signaling. J. Biol. Chem. 273: 23750-23757.

43. Downing GJ, Kim S, Nakanishi S, et al. (1996) Characterization of a soluble adrenal phosphatidylinositol 4-kinase reveals wortmannin sensitivity of type III phosphatidylinositol kinases. Biochemistry 35: 3587-3594.

44. Ahmed A, Kilby MD. (1997) Hypoxia or hyperoxia in placental insufficiency? Lancet 350: 826-827.

45. Caniggia I, Winter J, Lye SJ, Post M. (2000) Oxygen and placental development during the first trimester: implications for the pathophysiology of pre-eclampsia. Placenta 21 (Suppl A): S25-S30.

46. Maruo T, Matsuo H, Otani T, Mochizuki M. (1995) Role of epidermal growth factor (EGF) and its receptor in the development of the human placenta. Reprod. Fertil. Dev. 7: 1465-1470.

47. Amemiya $K$, Kurachi $H$, Adachi $H$, et al. (1994) Involvement of epidermal growth factor (EGF)/EGF receptor autocrine and paracrine mechanism in human trophoblast cells: functional differentiation in vitro. J. Endocrinol. 143: 291-301. 